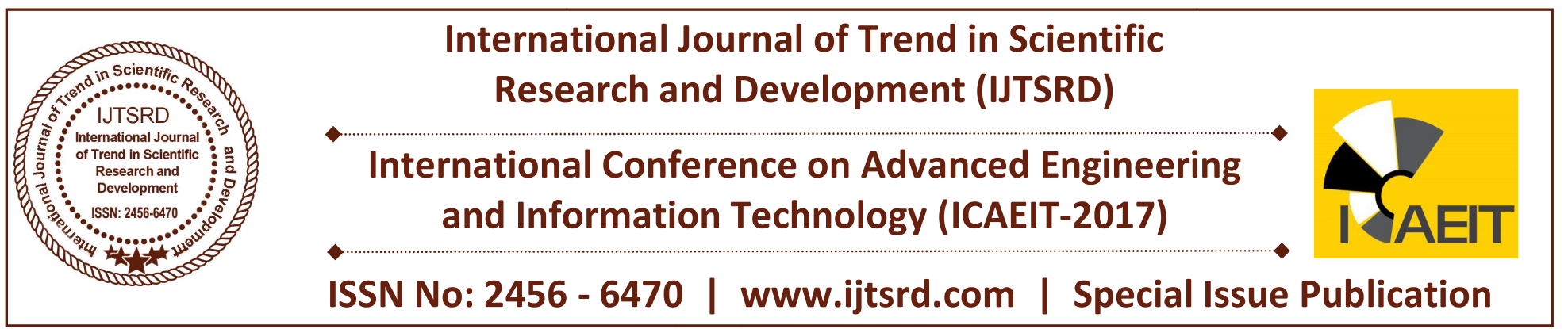

\title{
Identifying Motivational and Demotivational Factors in Qatar Construction Project Management Practices
}

\author{
Hamza. ${ }^{1}$, Deepak T. J. ${ }^{2}$, Maria. Josephine ${ }^{3}$, W., Parameswaran. $S^{3}$, Venishri. $P^{3}$ \\ ${ }^{1}$ UEL Student - Faculty of Built Environment, Linton University College, Mantin, Negeri Sembilan, Malaysia \\ ${ }^{2}$ Associate Professor, Dean Faculty of Engineering and Technology,Linton University College, Mantin, \\ Negeri Sembilan, Malaysia \\ ${ }^{3}$ Faculty of Business and Accounting, Linton University College, Mantin, Negeri Sembilan, Malaysia
}

\begin{abstract}
Motivation is one of the factors that influence the productivity of people. Project Managers, Engineers and Laborers, play a vital role in the management of projects in a Qatar Construction Industry (QCI). The success of these projects relies profoundly on their active participation and effective performance. Hence it is important to assess the impact of motivation and demotivation on the performance. The broad objective of this work is to assess the impact of motivation and demotivation in QCI. The specific objective of this paper is identifying the key factors that cause motivation and de-motivation in QCI. Literature review, survey with expert opinion and semistructured interviews were conducted to identify these factors. Using these factors to conduct specific motivational programmes will help in improving the productivity of people on a project.
\end{abstract}

Keywords: Motivation, Demotivation, Project Managers, Engineers, Loborers, QCI, Productivity.

\section{INTRODUCTION}

Project management has been in practice thousands of years, though it has been evolving in the $20^{\text {th }}$ century. Corresponding to the argument, be it Egyptians pyramid or the great wall of china, the emperors appointed civilians, soldiers and criminals to compete the construction with the division and management of different projects. The concept of project management has been more critical during the Industrial revolution and the introduction of the classical management theories which paved way in the most extensive and exclusive way of development of projects. The industrial revolution has been a wider remark in the history because of the emergence oil rich countries of the East. The evolution has been tougher and complex with the emergence of Globalization. The virtual and current modernization in the Middle East construction and built environment has evidenced a greater recognition and growth in the management of projects.

Its quite surprising to note that Qatar is a developing country however, the country's GDP is $\$ 143,788$. The country is an exceptional case when it counts with the relationship with the developing country and GDP. The reason for being an exception case is majority of the citizens enjoy the luxuries of the developed world with their elite lifestyles. The reason for being a developing country is the gap between the extreme poverty and extreme richness which had led to HDI of 0.85 pushing it to the category of developing country. One of the reason behind is low index is its excess expenditure on the Infrastructure projects. Thus, brings the significance of the project management in the country along with the recent announcement of FIFA 2022 World Cup hosting rights. Therefore, identifying the pertinent factors demotivating the project management success in Qatar construction has been taken as the main area of the study.

Therefore, the objective of this research is to identify, motivational and demotivational factors in Qatar construction project management practices. 


\subsection{Global Context}

According to a recent survey construction projects are accepted as a prominent factor in many industrialized countries which contributes to the economy of the country (Proverbs \& Olomolaiye, 1999). 10\% of national income in most of the developing countries has been a contributed by construction industry (Navon, 2005). Therefore, the contribution of construction industry has been more significant in the developing countries compared to the developed countries. Thus, bringing the significance of project management in construction industries in the developing countries.

\subsection{Project vs Project Management}

According to Stanley E. Portny (2013), Projects have been around for ages. For example, the ark built by Noah, Mona Lisa painted by the famous Leonardo Da Vinci, the Decline and Fall of the Roman Empire written by Edward Gibbon, the polio vaccine developed by Jonas Salk - all projects. These were all huge projects and very successful ones. Laurie S. Keller \& Mike Field (1998) definition of Project is that it is methodized task headed for a predefined target which depends upon resources and effort, a unique and risky venture containing a schedule and budget.

Joan Knudson \& Ira Bitz (1991) stated that a project is a properly methodized product which advances stage by stage having a beginning, end and a deliverable like a ladder where every step is crucial.

PMI's edition of PMBOK (2000) defines Project as a temporary group activity designed to produce a unique product, service or result. It has a definite beginning and end in time, and therefore specified scope and resources. The project is unique which means that it is not a routine operation, but a specific set of operations designed to accomplish a singular goal. Therefore, project teams are made up of staffs who are not even working all together - sometimes from different organizations and across multiple geographies.

Stanley E. Portny (2013) further states that a project is a brief task implemented to create a unique service, product, or result. The following three components are part of every project:

$>$ Schedule: timetable with dates stating the project beginning and end

$>$ Required Resources: the crucial elements such as number of staff, investment and other resources
$>$ Specific Scope: Desired result or product

$>$ Larry (2002) describes project as short lives since it has a beginning and an end.

$>$ Five Main Characteristics of a Project

$>$ A Defined Beginning, End, Schedule, and Approach

$>$ All resources are specifically allocated to the work

$>$ Results have specified goals such as (cost, time, performance/quality)

$>$ A planned and organized approach is taken

$>$ A group of people are involved

There is always a distinction between project and project management. A project is a series of activities established to achieve the specific objectives and consumes resources over a period of time. A project should be completed within a specified time and it has a definite start and end period whereas, project management is a concept where in a set of rules and regulations has been applied to control the routine operation of the company (Munns \& Bjeirmi, 1996).

Jack J. Phillips, Wayne Brantley, and Patricia Pulliam Phillips (2012) definition of Project management is that it is not a new idea or concept. Project Management is as ancient as the Egyptian pyramids. The magnificent pyramids built by the Pharaohs in ancient Egypt used procedures that remain in mystery today.

John J. McKeon (2011) describes Project management in his book "Becoming a Construction Manager" as "applied to a construction project, the use of integrated systems and procedures by the project team to accomplish design and construction. Project management is an integral function of construction management." Whereas, construction management is defined as a professional management practice towards construction projects, from project initiation to completion, for the intention of monitoring time, cost, scope and quality (John J. McKeon 2011).

MPUG's (2013) definition of Project management or program management as it is sometimes called is that it is the technique of arranging the elements of a project, whether the project is improvement of a recent brand, the establishment of a new operation, an advertising campaign, or even a wedding. A project is not a part of a daily routine. It's designed once, it's brief, and it's precise. A professional engineer describes it as, "It has a beginning and an end." A 
project uses up all the resources (such as materials, personnel, funds or time), and it has investment restrictions. (MPUG 2013).

PMI, which is known as world's leading professional society for project management, defines Project Management, in their guide PMBOK (2000), then, as the practice of linking techniques, skills and knowledge to complete projects effectively and efficiently. It's an important approach for organizations, which enables them to link project outcomes to business goals which gives them the edge in the business hub (PMBOK 2000).

Joan Knudson \& Ira Bitz (1991) states that Project management is required for the effective management to produce results in an appropriate and goal specific environment since it consists of a guideline with principles, methods, tools and techniques. Techniques such as good negotiation, communication and analytical skills are crucial part of this approach.

In the world of today, project management is becoming a crucial approach and if followed properly it is one of the key elements for project success. Project management enables managers to design and handle vital decisions which create new gains in expanding divisions of the market. Project management serves as a guide tool which helps to minimize time to market, control expenses, assure quality in products, and increase revenues. Larry (2002) suggests "Project management is one of the most important management techniques for ensuring the success of an organization."

Gary Picariello (2013) says Project management is a set of guidelines containing tools which allows managers to guide a project from one point to another and do so in an effective way that demonstrates efficiency, cost-savings and plain 'old ingenuity'. (Gary Picariello 2013)

As mentioned before, project management has been there as far as human existence goes. Before any activity takes place, there is always a thought given to how it will be carried out and whether it is being carried out the correct way. This is called Planning and is the initiative stage in project management. Then, after a lot of thinking it is carried out, and this is called execution. From simple concepts such as making a cup of tea, to much more complex ideas like skyscrapers, if a proper planning, management and execution is not done, then it will be a project failure. Just like a game of chess, one bad move and you lose! This is why careful planning and proper scheming has to be done in order to achieve the best results.

Gale \& Fellows (1990); Ofori (1990) suggest that the Construction industry in all countries faces many difficulties and challenges. Brian Miller (2012) says "The purpose of project management is to foresee or predict as many dangers and problems as possible; and to plan, organise and control activities so that the project is completed as successfully as possible in spite of all the risks." His research concludes that an ideal project is one in which three objectives are successfully achieved: Performance and Quality, Budget and Time Completion.

According to Gary Picariello (2011), he regards the relationship between the project manager, client and worker as very crucial to project success. He further states that knowledge, skills, tools and techniques of the three mentioned will deliver a successful project.

In line with the article written by Gary Picariello (2011), the following are stated as the key advantages of project management:

Improved Efficiency in Carrying Out the Project: Project management serves as a guideline that is easily followed and leads to project completion.

\section{Customer Satisfaction has increased:}

A customer is always glad and satisfied whenever a project is carried out on time and within the available budget. Intelligent project management provides the guidelines and tools that enable the customer and project manager relationship to flourish.

\section{Improved Effectiveness in Delivering of Services:} The steps are approximately the same for every project just the working environment and the situation is altered.

\section{Project Success brings in confidence, growth and development within the team:}

Positive results bring in respect and inspire the team to continue to search for ways to perform more efficiently.

\section{A Competitive Edge in the Business Hub:}

A successful and excellent performance is always required to gain a fair share of the construction market. 


\section{Chances to Grow the Company:}

Successful projects always lead to new chances to grow in the market.

\section{More Elasticity in Approach is Available:}

Project Management has a wide scope and a lot of approaches can be taken depending on the situation.

\section{Risk Assessment Increases:}

Project Management provides the necessary risk assessment to be taken before project initiation as that assists to avoid mistakes.

\section{Quality is Raised and therefore there is Increase in Quantity:}

Effective Project Management means a raise in quality work. Increase in quality is often the result of better efficiency

Gary Picariello (2011) further states that when project management strategies are put into action, the desired goals are achieved and the best thing is that it is within the specific time and cost perimeters. It provides the most essential guidelines required for a successful project.

Donald S. Barrie \& Boyd C. Paulson (1992) refers to Project Management as a modern-day tool which has perfected the projects in construction industry bringing in more organization and discipline and a smoother flow of work. The following are the factors which are vital to the success of project management as researched by Hubbard, (1990); Jaselskis and Ashley, (1991); Belout (1998); Chua et al. (1999); Walker and Vines, (2000):

$>$ Communication among the project team members

$>$ Implementing an effective health and safety program

$>$ Control of sub-contractors works

$>$ Overall managerial actions.

$>$ Feedback capabilities

$>$ Planning effort

$>$ An appropriate organization structure

$>$ Control Mechanism

As a host of FIFA world cup 2022, it is highly vital to identify the demotivational factors in Construction industry in order to mark the success of the country. With huge limitations of time constraints and the short time burden, it becomes an increasing burden to the host to mark for a quality project. Conjoint to this, the literature has attempted to derive the factors identified as demotivational factors that might be a hindrance for success in project management of FIFA world cup 2022.

\section{Research Method}

This research is carried out in two phases: a) Investigation phase and b) Survey phase. The details of both these phases are explained below: in Figure 1 illustrates the details of the investigation phase. Based on the literature survey and expert opinion, a list of factors influencing motivation and demotivation was prepared. Expert opinions were sought from the senior engineers with 10 years of field and administrative experience as well as the faculty guiding research studies in human resource management. Subsequently, semi-structured interviews were conducted to narrow down the list and identify the key motivating and de-motivating factors.

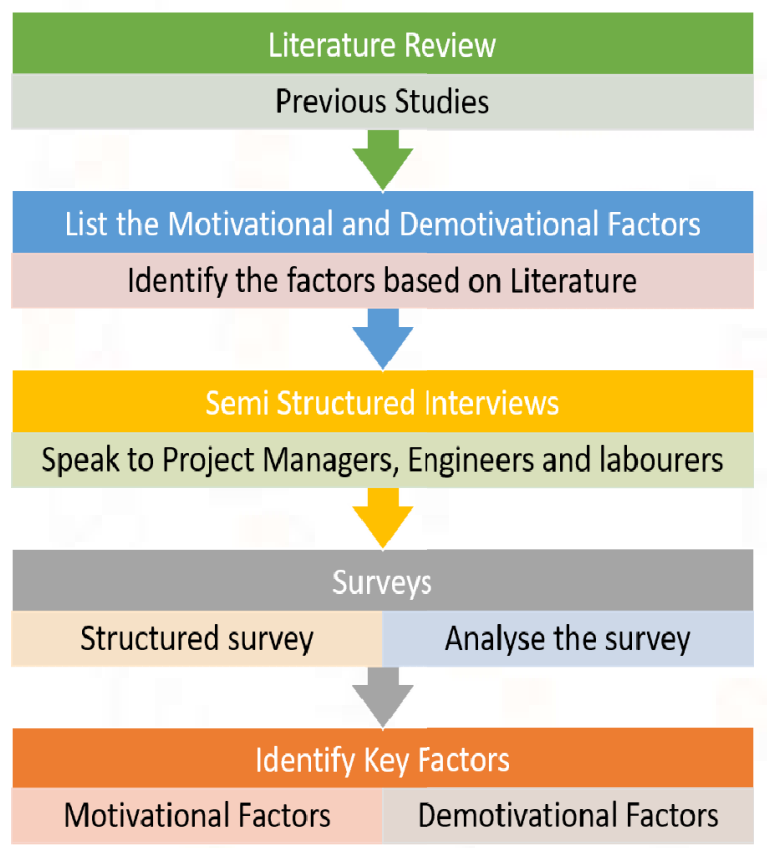

Figure1: Project Phase

\subsection{Motivational Factors}

Six key Motivational Factors were identified and are listed below.

i. Achievement

ii. Proper Recognition and rewards

iii. Interesting work

iv. Involvement in Decision Making

v. Professional Advancement

vi. Adequate Training and Development

The study identified six key motivational factors. Out of these, the four factors 'achievement', 'interesting work' 'proper recognition and awards' and 
'advancement' were selected from the Herzberg's two factor theory (1968). According to the experts' suggestions, 'growth', 'responsibility' and 'advancement' were combined as a single factor 'advancement'. The other two factors are 'participation in decision making' and 'adequate training and development' were taken from literature (Borcherding, 1977; Soura and Singh, 1998; Ruthankoon and Ogunlana, 2003) and ratified by the experts and field engineers. In the survey phase, these factors were presented to 30 Engineers, 15 Project Managers and 30 Clients. As outlined in the methodology, the respondents were met individually and were asked to make pair-wise comparison for importance between each set of key factors through structured questionnaires.

\subsection{Demotivational Factors}

Eleven key Demotivational Factors were identified and are listed below.

1. Poor Work Condition

2. Poor Administration Policy

3. Poor Work Relationship

4. Lack of Communication (English Language)

5. Lack of Appreciation

6. Comparing Colleagues over Benefits Received

7. Poor Labour Productivity

8. Lack of Materials at Site Area

9. Climate and Weather

10. Reworks and Variation of Orders

11. Leadership Styles and Strategies

Six key de-motivational factors such as 'Poor work condition', 'poor administrative policy' and 'Poor work relationship' were selected from the Herzberg's two factor theory (1968). The factor 'Comparing Colleagues over Benefits Received' was obtained from Adam's equity theory (1965). 'Lack of communication' and 'lack of appreciation' were derived from other established studies (Borcherding, 1977; U.S business roundtable proceedings, 1982).

In context to the demotivational factors, English language played a significant aspect in project management. With regard to the arguments concerning Qatar, the multinational task force has faced a severe communication problem in terms of English language. As communication can play a major threat towards the success of a project and its delay in the construction. There should be clearly defined communication and clear explanation with regard to the project management.

\subsubsection{Poor Labour productivity}

The core input to produce optimum output in a construction industry is its labour. As labour is considered to be the most efficient and value- driven output in a construction industry (Hwand \& Soh, 2013).

Jarkas, Kadri \& Yoounes(2014) has identified inappropriate recommendations and specific strategies are the demotivational factors in project management. However, there were still arguments that with the advanced technological factors, construction industry still remains as labour intensive (Jarkas, Radosavljevic \& Wuyi, 2014). According to a survey in Qatar, $82 \%$ of the engineers opined that poor labour productivity is one of the prime reason behind the failure of the projects and excess expenditure on the budget (Jarkas \& Haupat, 2015).

Poor management of the workforce would result in labour productivity. The construction engineers should definitely focus on the strategies to improve the labour productivity. The labour productivity has several related factors that includes, long working hours, job satisfaction, leadership, commitment towards organization and work engagement (Jarkas \& Haupt, 2015; Jarkas, Radosavljevic, et al., 2014, Jurf \& Beheiry, 2012).

In order to organize the FIFA world cup, Qatar has a long way to address the issues and identify the demotivational factors in the project management.

\subsubsection{Lack of materials}

Lack of material is an interlinking factor that causes low labour productivity that influence the demotivation factors in project management in construction industry. Lack of materials at the site area causes delay in the work and makes the workers to fall in the category of idle working hours (Mahamid, 2013). There were multiple factors that remains as an obstacle for the lack of materials in the construction area, which includes the shortages of materials, political triggers and monopolies in the suppliers. Qatar is no exception to these aspects as it may have a severe downfall in the situation relating to lack of materials. Lack of materials is one of the common obstacles in construction companies which affects their competitiveness and productivity (ElGohary \& Aziz, 2014). Jarkas, Radosavljevic \& Wuyi (2014) has also identified that shortage of raw 
materials has been main factor leading to a project failure and delay (Deepak \& Mommade, 2017).

\subsubsection{Reworks and Variation of Orders}

Frequent change orders and rework from the clients also cause the delay in the productivity of the project in the construction industry. The factors that includes the reworks includes revised drawings in the design and the layout plan which might lead to the project delays as well as low productivity consequently leading to project demotivational factors in the construction industry. This leads to variation of order in contracts. The Drawings quality and level of rework has contributed to the project failure as it consumes more time and consequently results in a project failure (Jarkas, et al., 2014).

\subsubsection{Climate and Weather conditions}

Chinnadurai, Venugopal, Kumaravel and Para mesh (2016) has argued that the temperature and weather condition are significant issues that influences the labour productivity. An increase in temperature has negative effect on the productivity in the construction industry. The speed of the work decreases with the increase in temperature in cold and hot weather (Moselhi\& Khan, 2012).

\subsubsection{Leadership styles and Strategies}

Determination of leadership style for the success is very challenging aspect concerned with the project management. Conversely it influences the productivity (Arshi Shakeel \& Sameh Monir, 2006; Enshassi et al., 2007b; Enshassi et al., 2009). Though, in a project management the determination of the leadership can be task oriented and relations-oriented. However, it is very difficult to determine the best leadership style in a project which suits the nature of the project. As there are different arguments concerning the authentic leadership styles and authoritive leadership style and its impact on project management. It is very difficult to determine the strategies. There should be positive and motivative leader to lead the team with high sense of ethic and morality which can lead to the success of a project management.

\section{CONCLUSIONS}

This study identified the key factors that motivate and de-motivate the construction industry in Qatar. The study shows the findings of Herzberg's theory to be relevant to the engineers in Qatar construction Industry. Intrinsic motivators comparatively play a vital role for many workers in any projects. The interesting nature of the construction work has to be properly utilized by the organization along with providing achievable goals to improve the motivation level. Similarly, the organization has to address the poor administrative policies and the poor work conditions to reduce de-motivation.

Further study about the key factors will help in identifying the underlying reason for more detailed analysis. These reasons should be used to evaluate the root cause of the problem. Thus, the organization can plan their motivational programs based on these details with periodical assessment to induce motivation and reduce de-motivation.

\section{REFERENCES}

1. Abdulaziz M. Jarkas, Milan Radosavljevic, Liu Wuyi, (2014) "Prominent demotivational Factors influencing the productivity of construction project managers in Qatar", International Journal of Productivity and Performance Management, 63(8), pp.1070-1090, https://doi.org/10.1108/IJPPM-112013-0187.

2. Chinnadurai, J., Vengugopal, V., Kumaravel, P., \& Paramesh, R. (2016). Influence of occupational heat stress on labour productivity - a case study from Chennai, India. International Journal of Productivity and Performance, 65, 245-255.

3. El-Gohary, K. M., \& Aziz, R. F. (2014). Factors influencing construction labor productivity in Egypt. Journal of Management in Engineering, 30(1), 1-9.

4. Jarkas, A. M., \& Haupt, T. C. (2015). Major construction risk factors considered by general Contractors in Qatar. Journal of Engineering, Design and Technology, 13, 165-194. doi:10.1108/JEDT-03-2014-0012

5. Jarkas, A. M., Kadri, C. Y., \& Younes, J. H. (2014). A survey of factors influencing the Productivity of construction operatives in the State of Qatar. International Journal of Construction Management, 12(3), 1-23. doi:10.1080/15623599.2012.10773

6. Jarkas, A. M., Radosavljevic, M., \& Wuyi, L. (2014). Prominent demotivational factors influencing the productivity of construction project managers in Qatar. International Journal of Productivity and Performance Management, 63, 1070- 1090. Doi: 10.1108/IJPPM-11-2013-0187. 
7. Jurf, N. A., \& Beheiry, S. (2012). Factors affecting cost and schedule in Qatar's residential Compound projects. International Journal of Engineering Management and Economics, 3, 117134. doi:10.150/IJEME.2012.048608

8. Mahamid, I. (2013). Contractors perspective toward factors affecting labor productivity in building construction. Engineering, Construction and Architectural Management, 20, 446-460. Doi: 10.1108/ECAM-08-2011-0074.

9. Moselhi, O., \& Khan, Z. (2012). Significance ranking of parameters impacting construction labor productivity. Construction Innovation, 12, 272-296. doi:10.1108/14714171211244541

10. Navon, R. (2005). Automated project performance control of construction projects, Journal of Automation in Construction 14, 467-476.

11. Proverbs, D. G.; Holt, G. D.; Olomolaiye, P. O. (1999). Factors impacting construction project duration: a comparison between France, Germany and the U.K., Journal of Building and Environment 34, 197-204. 